\title{
Haemomediastinum in a haemophiliac after minor trauma
}

\author{
S. K. M. JIVAN I and J ILLIA N R. M A N N \\ Birmingham Children's Hospital, Ladywood Middleway, Birmingham 16
}

\begin{abstract}
Haemomediastinum is a very rare complication in haemophilia. Its occurrence after a minor chest injury in a boy aged 11 years is described. Complete recovery followed conservative treatment, which consisted of the correction of the coagulation defect with cryoprecipitate-AHG for 11 days, and a blood transfusion.
\end{abstract}

Severe haemophilia is characterized by episodes of bleeding which may be spontaneous or traumatic in origin. This commonly results in haemarthroses and muscle haematomata, but occasionally serious internal bleeding (for example, retroperitoneal or subdural) occurs.

We have recently encountered the very rare complication of haemomediastinum in a known haemophiliac. The occurrence of haemothorax has been reported (Barrett and Israels, 1965) and two examples of haemopericardium have been described (Anderson, 1964 ; Gaston, Mach, and Beck, 1961). However, haemomediastinum has been recorded previously only in association with bleeding in the neck, from which blood tracked into the mediastinum (Edmonds, 1951 ; Pochedly and Rosales, 1968). The purpose of this report is to describe the occurrence and treatment of haemomediastinum arising in a haemophiliac boy after a minor chest injury.

\section{CASE REPORT}

An 11-year-old boy was found to be a haemophiliac at the age of 15 months when excessive bruising after slight trauma was investigated. He has no detectable Factor VIII activity in the plasma and has suffered numerous bleeding episodes, including haemarthroses, haematuria and a retroperitoneal haematoma.

On the morning of 18 August 1969 he developed pain in the right shoulder and stiffness of the neck. and later that day he complained of pain in the right side of the chest around the nipple area. The pain was of gradual onset, then radiated to the front of the chest and was made worse by deep breathing. In the evening he was admitted to hospital, where he was found to be febrile (axillary temperature $100^{\circ} \mathrm{F}$.) and tachypnoeic, with a respiratory rate of 40 per minute. The remainder of the physical examination was negative and a chest radiograph was normal. No history of trauma could be obtained and there was no clinical evidence of haemorrhage to account for his symptoms. Treatment with tetracycline was begun and by the next day his condition appeared to be improving though some pleuritic pain persisted.

Two days later slight swelling and bruising of the root of the neck were noticed and he became more dyspnoeic. The pain across the praecordium increased and repeat chest radiography revealed widening of the mediastinum and the presence of a small amount of fluid in each pleural cavity. At this point the boy remembered that he had fallen and banged his chest against some railings while fishing on the day before the onset of this illness. A diagnosis of traumatic haemomediastinum, with extravasation of blood into the root of the neck, was made.

The boy was transferred to the regional haemophilia centre and on arrival was pale (haemoglobin $7.6 \mathrm{~g} . / 100 \mathrm{ml}$.) with a tachycardia (pulse rate 132 per minute) and a blood pressure of $95 / 60 \mathrm{~mm}$. $\mathrm{Hg}$. The neck was diffusely swollen and showed slight bruising above the sternal notch. Superior vena caval compression was present, the jugular venous pressure being $6 \mathrm{~cm}$. above the sternal angle. There was, however, no evidence of pericardial effusion or cardiac tamponade. Dullness to percussion was present over both lung bases. A further chest radiograph confirmed the clinical findings; in addition, there was an opacity in the left lower lobe, thought to be due to intrapulmonary haemorrhage (Fig. 1).

Initial treatment consisted of cryoprecipitate-AHG, 9 units intravenously ( 1 unit=yield of Factor VIII concentrate from 1 pint $(0.57$ litre $)$ of blood), together with 3 pints ( 1.7 litres) of blood. Thereafter 12-hourly intravenous injections of cryoprecipitate-AHG were given for 7 days in doses adequate to maintain the plasma Factor VIII level above $10 \% ; 6-8$ units 12 hourly was required. Daily doses were continued for a further 4 days. We tested for the presence of inhibitors of Factor VIII in our patient's plasma and none was found.

Progress was satisfactory, with relief of the chest pain within 36 hours. The cervical swelling dis- 


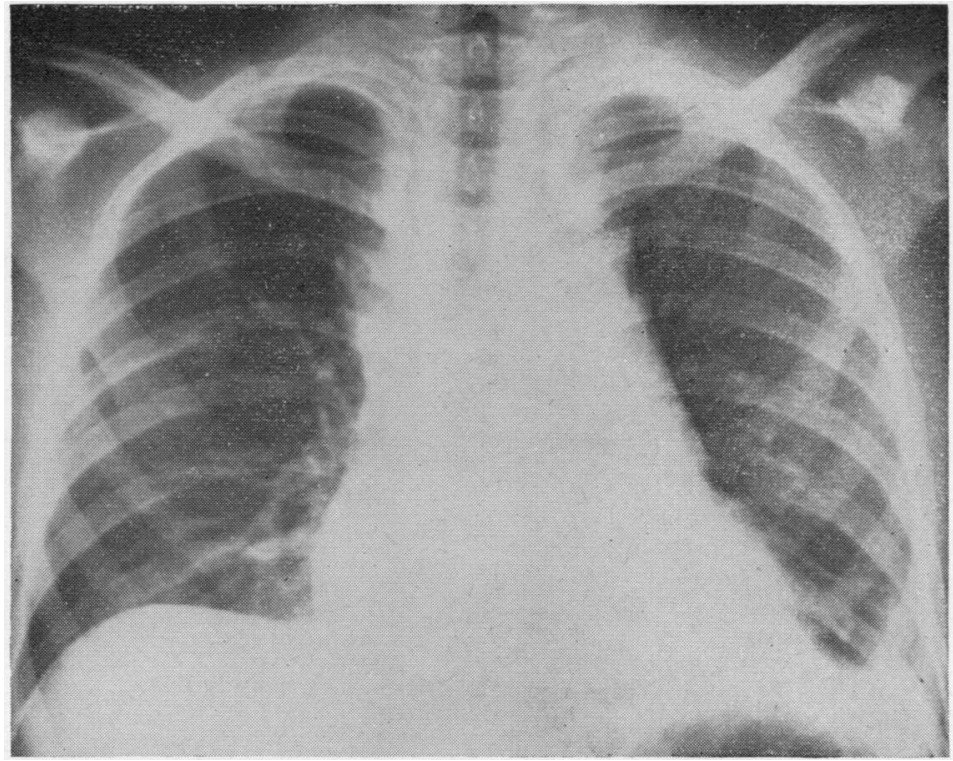

FIG. 1. Chest radiograph showing widening of the upper mediastinum and opacity in the left lower lobe.

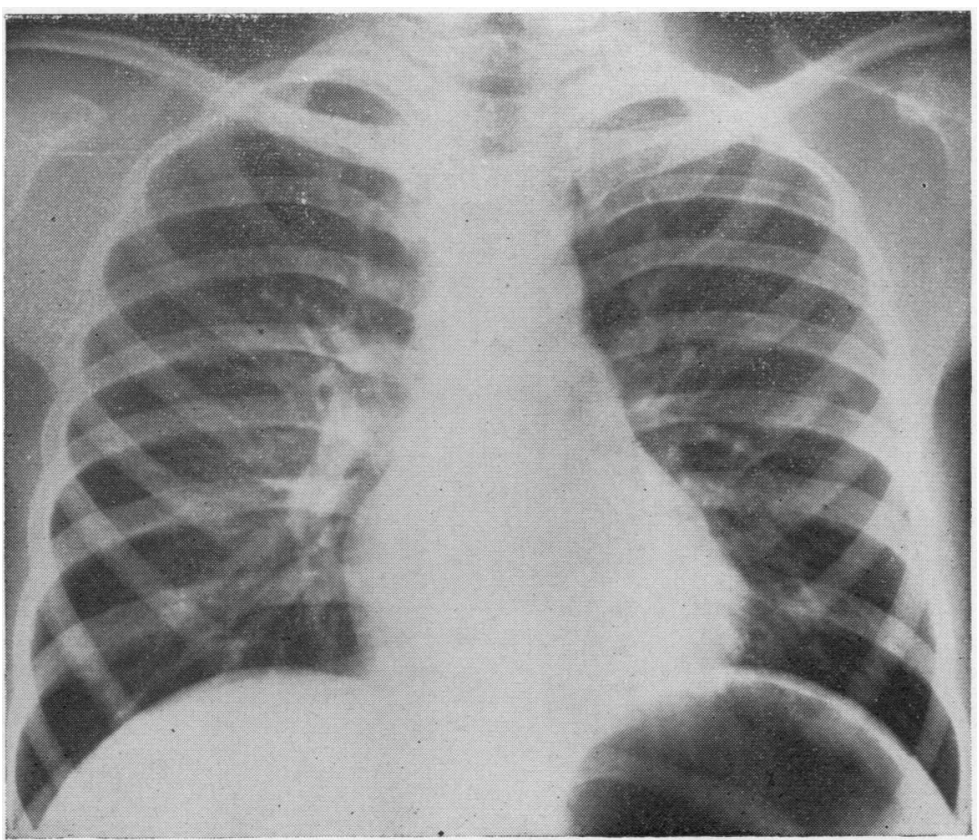

FIG. 2. Chest radiograph after completion of therapy. 
appeared within 72 hours and the jugular venous pressure returned to normal. Radiographs of the chest showed steady improvement and had returned to normal 12 days after commencing cryoprecipitateAHG therapy (Fig. 2).

\section{COMMENT}

Considerable trauma is required to cause haemomediastinum in the normal individual and cardiac contusion may be present. Radiological examination usually reveals broadening of the mediastinal shadow and a fracture of a lower cervical or upper thoracic vertebra. The position of the trachea is important (Sandor, 1967). If the trachea is deviated to the right the haemomediastinum is likely to be the result of an aortic injury and aortography is indicated. In our patient there was only slight trauma which had in fact been forgotten by the child. There was no evidence of a fracture of either the ribs or vertebrae, the trachea was central and there was no evidence of an injury to the aorta.

Experience with this child suggests that in haemophilia the management of haemomediastinum should be directed towards the correction of the bleeding disorder, and a blood transfusion should be given if required. In our patient, the

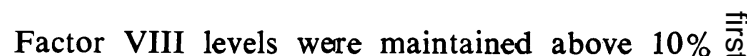
for over a week, using the Factor VIII concentrate $\overline{0}$ cryoprecipitate-AHG, and as a result the bleeding stopped and the blood in the mediastinum and $\frac{\bar{\omega}}{}$ pleural cavities was reabsorbed. Surgical $ه$ measures were not required.

We are indebted to Drs. M. E. MacGregor and G. W. Chance for permission to report this case, to $\vec{\omega}$ Drs. R. Astley and F. G. O. Burrows for the chest $O$ radiographs, and to the Regional Blood Transfusion Service for supplies of cryoprecipitate-AHG.

One of us (J. R. M.) was in receipt of a Research ô Fellowship financed by the United Birmingham Hospitals Endowment Fund.

\section{REFERENCES}

Andersen, G. A. (1964). Spontaneous hemopericardium with cardiac tamponade and 'pericardiotomy syndrome' complicating hemophilia. Amer. J. Cardiol., 13, 278.

Barrett, K. E., and Israels, M. C. G. (1965). Haemothorax in haemo- $\vec{\theta}$ philia. Thorax, 20, 416 .

Edmonds, A. R. (1951). Death from respiratory obstruction in haemophilia. Med. J. Aust., 1, 227.

Gaston, L. W., Mach, B. F., and Beck, W. S. (1961). Hemophilia $A$ and concurrent Factor VII deficiency. Studies of a patient with complicating cardiac tamponade. New Engl. J. Med., with complicating cardiac tamponade. New Engl. J. Med.,
264, 1078.

Pochedly, C., and Rosales, A. (1968). Respiratory obstruction in a child with classical hemophilia. Amer. J. Dis. Child., 116, 103.

Sandor, F. (1967). Incidence and significance of traumatic medi- Q astinal haematoma. Thorax, 22, 43 . 